\title{
Después de 1848: \\ Flaubert, Huysmans y el problema del canon
}

\author{
Alejandro GOLDZYCHER ${ }^{1}$ \\ Universidad de Buenos Aires (Argentina) \\ Facultad de Filosofía y Letras, Departamento de Letras \\ agoldzycher@filo.uba.ar
}

Recibido: 30/10/2013

Aceptado: $12 / 04 / 2014$

\begin{abstract}
Resumen
Entre los ensayos de periodización del siglo XIX, la elaboración imaginaria del año 1848 ha cumplido un rol preponderante. De ahí la difundida concepción del siglo como díptico, reconociéndose en cada una de sus mitades una "atmósfera" específica. Este trabajo se propone explorar los términos en que este supuesto crítico ha operado desde el propio fin-de-siècle, tomando como referencia las respectivas figuras de Flaubert y de Huysmans en función de su adscripción a tales o cuales cánones estéticos. Así, a aquel primer dualismo habrá que sobreimprimir otro, en su caso asociado a las supuestas tradiciones del "realismo" y del "fantástico", que los mitos del "48 debieron absorber o incluso ignorar. Cabe esperar, entonces, que esta cartografía crítica contribuya a problematizar la comprensión histórica de la cultura decimonónica, desde el francocentrismo de ciertas periodizaciones al verosímil crítico que aproximaciones ya canónicas han contribuido a naturalizar.
\end{abstract}

Palabras clave: Año 1848, romanticismo, canon, historia cultural, fin-de-siècle.

\section{Après 1848: Flaubert, Huysmans et le problème du canon}

\section{Résumé}

Parmi les essais de périodisation du XIX ${ }^{\mathrm{e}}$ siècle, l'élaboration imaginaire de l'année 1848 a joué un rôle primordial. D'où la conception du siècle en tant que diptyque, et la reconnaissance, pour chacune de ses moitiés, d'une «atmosphère » spécifique. Le but du présent travail est celui d'explorer les termes dans lesquels ce présupposé critique a opéré depuis la « fin de siècle », en prenant comme point de référence les figures de Flaubert et de Huysmans, en fonction de leur adhésion à des canons esthétiques déterminés. Ainsi, il faudra surimprimer un nouveau dualisme sur le premier, en ce cas associé à des traditions du « réalisme » et du «fantastique », que les mythes du 1848 ont dû absorber, voire ignorer. Cette cartographie critique contribuera à problématiser la compréhension historique de

1 Alejandro Goldzycher participa del Proyecto UBACyT "Literatura y formas de vida" $\left(\mathrm{N}^{\circ}\right.$ 20020100100137), dirigido por el Prof. Daniel Link. Inscripto en el campo de las literaturas comparadas, el proyecto desarrolla la articulación entre "literatura" y "vida" a partir de la interrogación del estatuto del discurso literario, abriéndose a la vez a una indagación de la producción de "formas-de-vida" (referida aquí, en particular, a la categoría "autor") a través del concepto de "biopolítica". 
la culture du XIX ${ }^{\mathrm{e}}$ siècle, depuis le francocentrisme de certaines périodisations jusqu'au vraisemblable critique que les approches déjà canoniques ont contribué à naturaliser.

Mots clés: Année 1848, romantisme, canon, histoire culturelle, fin-de-siècle.

\title{
After 1848: Flaubert, Huysmans and the Problem of Canon
}

\begin{abstract}
Among the attempts to periodize the nineteenth century, the imaginary elaboration of the year 1848 has played a main role. Hence the widespread conception of the century as a diptych, a specific "atmosphere" being recognised in each of its halves. The present work proposes to explore the terms in which this critical assumption has worked since the fin-de-siècle itself, taking into account authors such as Flaubert and Huysmans by virtue of their adscription to certain aesthetic canons. Thus, it will be necessary to superimpose a second dualism to the first one, in this case associated to the supposed traditions of "realism" and the "fantastical", which the myths of 1848 have had to absorb or even to ignore. It is to be hoped for, then, that this critical cartography will contribute to question the historical comprehension of nineteenth-century culture, from the Francocentrism of certain periodizations to the critical verisimilitude that canonical approximations have already contributed to naturalize.
\end{abstract}

Keywords: Year 1848, Romanticism, canon, cultural history, fin-de-siècle.

Sumario: 1. El siglo como díptico. 2. "Orientaciones doctrinales". 3. Lukács y Hauser: espacios de conmensurabilidad. 4. "Realismo historicista" y "realismo existencialista". 5. Praz y el "Segundo romanticismo" 6. Rumbo al otro fin de siglo

\section{Referencia normalizada}

Goldzycher, A. (2014). "Después de 1848: Flaubert, Huysmans y el problema del canon". Thélème. Revista Complutense de Estudios Franceses, Vol. 29, Núm. 2: 327-344. http://dx.doi.org/10.5209/rev_THEL.2014.v29.n2.43295

\section{El siglo como díptico}

La visión del siglo XIX como un díptico articulado en torno al año 1848 no constituye, en principio, más que una entre muchas posibles. Ni siquiera es forzoso que se trate de la más importante, aunque bien podamos sospecharlo. La vigencia misma de su productividad como categoría crítica podría ser puesta en duda. No por ello deja de ser cierto que algunos de los hitos más significativos de la historiografía de la literatura y el arte -canónicos en cuanto a la configuración, precisamente, de ciertos cánones- han contribuido a alimentar aquellos esquemas dicotómicos; esquemas en los que podría reconocerse un movimiento, en parte inercial, capaz de fundamentar un lazo diacrónico entre la crítica de fines del siglo XIX, por un lado, y determinados autores de referencia del siglo XX, por el otro. A estos últimos cabría referir, en diverso grado, la observación que hizo Jaime Rest a propósito de Mario Praz: esto es, el hecho de haber sido capaces, aun en el marco de supuestas constricciones conceptuales, de "cumplir una empresa memorable, sin la cual 
resultaría mucho más difícil -acaso imposible- llevar adelante la tarea interpretativa desechada" (Rest, 1971: 25). Es hacia aquellos tópicos críticos, de raigambre a veces claramente decimonónica, que buscaremos orientar el presente artículo. Con este fin, tomaremos como referencia un corpus bibliográfico que, pese a su inevitable estrechez, nos permitirá no obstante delinear -a través del estudio de sus términos de discusión y de análisis- una cuadrícula de abordaje determinada.

Comenzaremos por objetivar la asunción de que, como dice Harvey, "Something very dramatic happened in Europe in general, and in Paris in particular, in 1848. The argument for some radical break in Parisian political economy, life, and culture around that date is, on the surface at least, entirely plausible" (Harvey, 2003: 2). Las antítesis entre una y otra mitad del siglo de inmediato comienzan a proliferar, de Delacroix y los neoclásicos a Courbet y Manet, de la ciudad cuasi-medieval al bulevar haussmanniano, de los utopistas al socialismo científico, de la novela romántica a Flaubert y Baudelaire. Pero incluso en el marco de estas oposiciones han regido distintos criterios de periodización. Jauss, por ejemplo, afirmó que "Para los contemporáneos de Baudelaire fue la primera exposición universal de 1851 'el suceso más poético y de mayor significación histórica de la época', mucho más que la fracasada revolución de 1848" (1989: 83). Postura tanto más interesante cuanto que no toma como referencia un acontecimiento eminentemente político, como podría ocurrir con los años 1830 o 1871, en cuyo caso el francocentrismo resulta, por lo demás, mucho más evidente. La adopción de una postura alternativa no implica, por cierto, restar preeminencia al '48: el mismo Jauss, pocas líneas más adelante, volvería a ese año como punto de referencia fundamental (1989: 85).

Los criterios varían, asimismo, de una disciplina a otra. De este modo, Samson - por citar sólo un caso- nota cómo tanto los historiadores de las artes visuales como los historiadores "a secas" habrían tendido a producir "a sense of 'two halves' of a long nineteenth century, each distinctively profiled" (2001: 19), mientras que los historiadores de la música habrían sido más proclives a figurar un largo siglo romántico, extendido entre Beethoven y principios del siglo XX. Otro tanto ocurre, quizás incluso con mayor intensidad, en el caso de la literatura. Si el año 1830 adquiere -por remitirnos únicamente al problema de lo nacional- un peso más evidente en las historias de la literatura francesa, tratándose del año del estreno de Hernani, no ocurre lo mismo en los casos de Alemania e Inglaterra, donde el romanticismo se habría encontrado ya consolidado. Así lo sostienen o incluso lo aceptan numerosos autores (cfr. Carboni, 2004: 80), en contraste con la postura más crítica de un Wellek (1968: 132). Pese a tales divergencias, las concepciones en torno a un siglo dividido entre dos "romanticismos", o entre una mitad "romántica" y otra dominada por cierto conjunto de "-ismos", no dejarían de exhibir ciertas constantes que será necesario analizar.

De éstas tomaremos, como punto de partida, la idea de que el llamado Year of Revolution (cfr. Rapport, 2009: 408) habría marcado algo así como una reconfiguración de la perspectiva histórica del romanticismo, ligada a la posibilidad de tomar distancia con respecto a éste incluso cuando se tratara, precisamente, de negar esa distancia. Así es como el romanticismo - tal como unos y otros críticos 
emplean el término- habría pasado a ofrecer, con una inmediatez cada vez mayor, su disponibilidad en carácter de una ascendencia cultural posible, más que necesaria, a propósito de un relato histórico determinado. Un relato que Hayden White no ha dudado en asimilar tanto a la Bildung del protagonista de L'éducation sentimentale (Flaubert, 1870 [1869]) como a la estructura de trama de El dieciocho Brumario de Luis Bonaparte (Marx, 2003 [1852]), identificando la misma con "una progresiva eliminación de los ideales para poder reconciliarse con una realidad concebida como el melancólico consumo de mercancías cuyo verdadero valor se mantiene indiscernible" (White, 2011: 330). Concebidas en función de su adscripción a tales o cuales cánones estéticos, las respectivas figuras de Flaubert y de Huysmans nos servirán como hilo conductor a través de nuestra indagación de este sustrato mítico, orientándonos al estudio de su inscripción en ciertas visiones del siglo XIX en su conjunto antes que a la profusa bibliografía específica a ellos consagrada, en cuyo caso cabría esperar una menor permeabilidad a los tópicos críticos en cuestión (dada la afinidad de éstos a las grandes generalizaciones).

Al emparejarse los nombres de ambos escritores, el desequilibrio entre los mismos salta a la vista. Es que, si bien la producción crítica en torno a Huysmans es más abundante de lo que podría suponerse (esta suposición sería, en sí, un indicio del citado desequilibrio), su situación jamás podría equipararse a la de Flaubert, salvo que -por razones tan hipotéticas como improbables- llegara a producirse un vuelco radical en la construcción de sus respectivas figuras autorales. Por un lado, Flaubert ha quedado establecido como uno de los "grandes autores", no sólo de la literatura francesa (tal como lo expresan su lugar en la colección La Pléiade o el interés que por él han demostrado pensadores igualmente "grandes" [cfr., v.gr, Sartre, 1971-72], por citar sólo dos ejemplos), sino del canon occidental en su totalidad; todos los críticos aquí mencionados le conceden un rol eminente en el desarrollo global de la modernidad estética. En contraste, veremos a Huysmans conservarse como un autor menor, por lo demás mucho más claramente anclado al ámbito de las letras francesas, desde el cual, en todo caso, su apellido y su obra se proyectan hacia otros ámbitos nacionales. No sorprende por ello que Huysmans se convirtiese ante todo -ya desde finales del siglo XIX- en "el-autor-de- $\hat{A}$ rebours", frente a la valoración más equilibrada de la obra flaubertiana. Lejos de obturar la configuración de un terreno de comparación, estos órdenes de asimetría nos permitirán aislar más eficazmente los presupuestos que han llevado al desarrollo de la figuras en cuestión a través de sendas de recepción notablemente diversas, y aun así atribuibles a esquemas dicotómicos comunes.

\section{2. "Orientaciones doctrinales"}

Nuestro empleo del concepto de "canon" requerirá, en este punto, una fundamentación específica, sobre todo en contraste con nociones tales como las de "serie", "sistema", "catálogo", "escuela", "corriente", "tradición" o incluso "período". En adelante, se tratará del canon entendido, ya no como conjunto de obras reconocidas por su excelencia (esto es, como "conjunto orgánico o articulado 
de libros que deben ser leídos por su valor estético", como dice Gamerro en su lectura de Bloom [Gamerro, 2003: 54]), sino como un determinado marco de intelección, quizás más general que el anterior, quizás también más intuitivo, incluso designado éste por términos alusivos a lo que, en primera instancia, parecieran constituir más bien escuelas o corrientes estéticas. Partiremos entonces de una noción de "canon" a primera vista más vaga que la anterior, concibiéndola ahora como referida a "a list of standard texts relating to a particular culture or area" (Gorak, 2013: 51). Tal vez la imagen de un "foco de irradiación" resulte aquí más descriptiva; el criterio sería el grado de "prototipicidad" que cierto elemento (típicamente, un autor o una obra) guardaría en relación con cierta categoría iluminadora, a su turno, de cierto campo fenoménico. De ahí la posibilidad de considerar vínculos de diferencia e incluso de exclusión como configuradores de un terreno común en medida igual o mayor que las relaciones de semejanza que puedan trazarse en el seno del material.

Puede concebirse, de este modo, la circunstancia de que -partiéndose de una categoría como "decadentismo"- el nombre de Zola resultase más prototípico, y por ende más ineludible, que el de un Élémir Bourges o el de un José Asunción Silva, aunque muy difícilmente llegase a serlo, según podría esperarse, que el de un Huysmans (a propósito del cual ha llegado a ser común, adoptada esa perspectiva, introducir la figura de Zola [cfr., v.gr., Praz [1999: 569]). Este último, en oposición al "decadentismo" como denominación positiva de cierta corriente estética, cuyos miembros podrán, en todo caso, considerarse más o menos "representativos" en relación con ella misma. Es a la luz de estas concepciones que veremos desplegarse un segundo estrato de análisis, en parte transversal con respecto al problema del ' 48 como eje del siglo, en parte una especificación de dicho problema. Se trata de la distinción entre dos grandes "vertientes" en la literatura decimonónica, orientada expresamente la una al problema de la dimensión representacional de la creación literaria en cuanto a la remisión de ésta a "la realidad", problematizando la otra el aspecto más ostensiblemente "imaginativo" de la literatura, adoptadas como referencia ciertas fantasmagorías cultivadas de manera sostenida desde finales del siglo XVIII (cfr. Praz, 1999: 50).

Así pues, si la heterogeneidad misma de la segunda "mitad" del siglo tiende a dificultar, para los autores en cuestión, su concepción como bloque si no es en relación con ese pasado "romántico", a este contraste fundamentalmente diacrónico se sumaría la figuración más o menos sincronicista de cierto conjunto de corrientes, agrupables de un modo u otro en función de aquellas dos grandes "vertientes". La vaguedad de estos términos quizás sea, por lo demás, en gran medida ilusoria. Y es que no sólo la crítica ha recurrido efectivamente a los mismos desde el propio siglo XIX, de modo que no se trataría de una simple categorización retrospectiva. (Ya decía Maupassant, con una ligera variante, que "Le naturalisme est aussi limité que le fantastique" [Kellner, 2012: 93].) Como ha notado Jaime Rest, "la adjudicación de adherentes no es (...) totalmente equívoca", de manera que "grosso modo la división es acertada o, por lo menos, bastante útil: hay una novela realista y una ficción esteticista" (Rest, 1977: 16). Pareciera ser también en ese sentido que Jauss, 
en su ensayo "El arte como anti-naturaleza. El cambio estético después de 1789", distinguió dos dicotomías por igual fundamentadas sobre la figuración de un pasado "romántico". A la división del siglo en dos mitades sobreimprimía aquél, en efecto, un segundo dualismo, identificado en su caso con las nuevas "orientaciones doctrinales" de la segunda "mitad" del siglo: el naturalismo y el simbolismo. Para Jauss, es Baudelaire quien habría cumplido "del modo más decidido el giro estético desde la belleza natural de la estética romántica al concepto moderno de arte como antinaturaleza" (Jauss, 1989: 116-118), inaugurando una línea extendida desde él mismo hasta Valéry, pasando por Comte, Marx, Engels, Huysmans o Mallarmé. Un índice de nombres que resulta, por otro lado, muy similar al que planteara Sartre en su Baudelaire (1967 [1946]: 103).

No en vano el problema de la clasificación en términos de "naturalismo" o "decadentismo" (ambos en oposición al "romanticismo" de la primera mitad del siglo) constituye, con diversos grados de complejidad, un lugar común en la bibliografia crítica dedicada a Flaubert y a Huysmans: en el caso del primero, más bien en términos de obras individuales (supuesto "decadentismo" de Salammbô, "naturalismo" en Madame Bovary, etc.), y en el de Huysmans, en relación con supuestas "etapas" de su obra. Aun así, y como parte del "desequilibrio" antes citado, cabe notar cómo la figura de Flaubert ha llegado exhibir un grado de inclasificabilidad capaz de hacerla trascender-salvo, como podremos comprobarlo, por la negación- cualquier movimiento o estética, configurándose como una suerte de "ciudadano de la literatura", por no decir de la cultura en general. Frente a esta fuerte dimensión sui generis atribuida a su colega normando (que llevó a Bourdieu a afirmar su oposición tanto "a Gautier y el Arte puro" como al "realismo", sin tratar de "conciliar los opuestos o de combatir los excesos de uno mediante los excesos del otro" [Bourdieu, 1995: 149]), el nombre del parisino se ha visto asociado, mucho menos equívocamente, a dos "escuelas" distintas -al "naturalismo" y al "decadentismo"- a su turno correspondientes con aquellas dos "etapas" (cfr. Stephan, 1974: 70-72).

A título eminentemente ilustrativo, organizaremos nuestro corpus en torno a tres ejes, consagrados cada uno a "clásicos" de la crítica del siglo XX. El primero, focalizado sobre textos de György Lukács y Arnold Hauser, exhibirá una voluntad más o menos marcada de exponer un espacio de conmensurabilidad entre las "orientaciones doctrinales" en cuestión, tratándolas de forma mutuamente simétrica y en común oposición a una primera "mitad" del siglo. El segundo eje, concentrado en Erich Auerbach, abordará los problemas referidos a partir de un material crítico explícitamente articulado en torno a la categoría de "realismo", observándose cómo funciona allí, a propósito de dicha categoría, la práctica ausencia del elemento "fantástico". En estos dos primeros casos, la concepción del vínculo entre los mundos ficcionales de la literatura y lo que se concibe como el "afuera" de los mismos seguirá a grandes rasgos la tendencia -señalada por Doležel- por la cual "fictional particulars, reduced to actual universals, disappear from semantic interpretations" (Doležel, 1988: 478). El tercer momento estará dedicado, en fin, a la que quizás sea la más renombrada obra de Mario Praz. En este caso, el foco se 
trasladará a una serie que el propio autor definió como "romántica", en relación con la cual se reducirá la presencia del "realismo" al mínimo, aun concebido aquél como contrapartida de aquella serie. En cuanto a la categoría "después de 1848" como eje articulador de los elementos en juego, su relegación (expresa o no) por parte de Praz en beneficio de otros factores organizativo-explicativos no hará más que permitirnos apreciar mejor, en este caso ex negativo, las proyecciones históricas del trabajo del autor italiano en relación tanto con su material como con otros trabajos críticos.

\section{Lukács y Hauser: espacios de conmensurabilidad}

En "La fisonomía intelectual de las figuras artísticas" (1936), Lukács afirmó que "lo nuevo de la época después de 1848 consiste en que la realidad cotidiana significa no sólo un tema, sino la limitación de la expresión literaria a las formas de manifestación y de expresión que pueden producirse en la realidad cotidiana" (Lukács, 1966: 140). El autor pareciera figurar aquí una dicotomía en gran parte análoga a aquella entre "fantástico" y "realismo", al asegurar que, en tal contexto, el cientificismo y el "romanticismo místico-fantástico", el naturalismo y la novela de "individuos excéntricos" (que Lukács percibía como reacción contra el primero, tomando al héroe de Huysmans como modelo), no habrían sido más que dos caras de una misma moneda (1966: 144, 145). Así también el positivismo ingresa, sin grandes rodeos, en este esquema. Al igual que las criaturas de Huysmans, pero también de D'Annunzio o de Maeterlinck, los "casos" o "ejemplos" figurados por el pensamiento científico de entonces "sólo pueden intuirse y comprenderse a sí mismos" (Lukács, 1966: 140). No extraña, así, que Lukács considerase al "superhombre" decadente y al filisteo (en este caso, el individuo común, "mediocre", que lleva la vida típica del consumidor moderno) como expresión de un mismo campo fenoménico. Ya Max Nordau, en su ineludible Degeneración (1892), había sentenciado: "The decadent snob is an anti-social Philistine" (Nordau, 1892: 307).

La voluntad lukacsiana de hacer funcionar el nombre de Flaubert a partir del esquema dicotómico planteado no podía sino involucrar una nueva instancia en la negociación de su figura autoral, reclamándose en este caso, de forma más o menos implícita, un oscurecimiento de la casi innegable faceta "fantástica" de la obra flaubertiana en beneficio de un Flaubert claramente "realista": sólo así se logra una oposición lo más paroxística posible entre las escrituras flaubertiana y zoliana devenidas expresión sinecdóquica de la segunda "mitad" del siglo- y el "subjetivismo" y "lo romántico-excepcional", cayéndose a la vez, de esta manera, en una naturalización de "lo corriente" como rasgo objetivo de lo real. Pronto, sin embargo, la posibilidad de una explicitación de la distinción objetivamente discutida entre un Flaubert "fantástico" y otro "realista" acaba perdiendo toda pertinencia posible, no sólo porque ha transcurrido ya el momento de la exposición en que podía admitirse aún -por razones heurístico-didácticas- la simplista figura de un siglo llanamente dual, sino también por reconocerse ahora el hecho de que, 
pudiendo aun hablarse de una persistencia e incluso de una intensificación de ciertas "corrientes irracionalistas" a partir de mediados de siglo, éstas habrían quedado indefectiblemente encerradas en una relación dialéctica con la corriente "objetivista" en virtud de esos mismos condicionamientos epocales que los opondrían, en conjunto, al tiempo de Balzac y Stendhal (Lukács, 1966: 143).

Análoga a la anterior resulta, en gran parte, la visión panorámica del siglo XIX que se ofrece en “¿Narrar o describir?” (1936). Allí, Flaubert y Zola (el primero, ahora, con mayor contundencia) vuelven a presentarse como encarnaciones típicas de "la época posterior de 1848" (Lukács, 1966: 177), en contraste con el tipo de escritura que condensarían las obras de Scott, Balzac, Stendhal, Dickens y Tolstoi. El criterio determinante en cuanto a la distinción entre unos y otros autores es, en este caso, la que marca la especialización del escritor como tal. En un nivel evidentemente más figurativo, se trata también del hecho de que tanto Flaubert como Zola "iniciaron su actividad después de la Batalla de junio, en la sociedad burguesa ya constituida y completada", pasando así a identificarse -a diferencia de aquellos otros autores- con el segundo término del "contraste entre el convivir y el contemplar" (Lukács, 1966: 177). Ante una sociedad burguesa "ya constituida y completada", "[Flaubert y Zola] sólo podían escoger como solución de la contradicción trágica de su situación el aislamiento" (Lukács, 1966: 179), convirtiéndose desde ese mismo lugar de observación crítica "en escritores en el sentido exclusivamente profesional, (...) en el sentido de la división capitalista del trabajo", legitimando de tal modo la mercantilización de las formas artísticas (1966: 179).

Menos orientada a factores quizás más específicamente "literarios" se muestra, en estos aspectos, la Historia social de la literatura y del arte (1951) de Hauser, retomándose empero la figuración de la segunda mitad del siglo como un a priori capaz de tergiversar incluso las mejores intenciones. Hauser distingue entre un pasado ante todo romántico y ciertas "corrientes" que se ha dado en considerar finiseculares, tales como el simbolismo (que habría rechazado el romanticismo "por su emocionalismo y por el convencionalismo de su lenguaje metafórico [Hauser, 1985: 227]) o "los decadentes" (para quienes, a diferencia de los románticos, "todo es abismo, todo está lleno de miedo a la vida y de inseguridad" [1985: 218]). Es cierto que 1848 aparece allí muy devaluado en relación con 1830, año en que, según el autor, se habría fundado verdaderamente el siglo XIX. No obstante, aquél conserva su carácter de bisagra en la medida en que, con su advenimiento, habría quedado clausurada toda una etapa de "politización creciente de la vida", literatura incluida (1985: 18). Entonces, el arte habría quedado sumido en el quietismo, y "los verdaderos artistas", totalmente alejados del público en el contexto de una "increíble pérdida de nivel en el pensamiento" y de un "embrutecimiento absoluto del gusto" (1985: 71, 72). En este marco, el autor no dudó en concebir la obra flaubertiana en clave de una reacción contra el romanticismo, al igual que el "decadentismo" (cuya aparición postergó hasta 1880, y en el que incluyó, despreciativamente, a Huysmans) y el "simbolismo" (al que presentó como sucesor del decadentismo) (cfr. Hauser, 1985: 218). 
Aunque el autor dispensase a Flaubert un tratamiento mucho más elaborado que a esas dos "corrientes", se distingue en el análisis de su obra los términos de abordaje que aquél había retomado, precisamente, a propósito de la literatura y el arte "decadentistas". Hauser invoca así la palabra de Paul Bourget, uno de aquellos autores del siglo XIX cuya producción ha resultado fundamental en cuanto a la constitución de un canon "post-1848". En sus Essais de psychologie contemporaine (1883), Bourget había visto en Emma Bovary y Fréderic Moreau "le produit d'une civilisation fatiguée" (Bourget, 1883: 144), e incluso añadía, trascendiendo la supuesta "oscilación" flaubertiana entre objetividad y esteticismo, entre "realistic spleen" y "romantic ideal" (cfr. Tollinchi, 2004: 128; Weir, 1995: 22): "Que Flaubert s'occupe du monde ancien ou du monde moderne, toujours il attribue à la Littérature, (...) c'est-à-dire à la parole ou à la lecture, le principe premier de ce déséquilibre" (Bourget, 1883: 148, 149), de Madame Bovary a Salammbô, de L'éducation sentimentale a Bouvard et Pécuchet. Es también Bourget quien resuena en la visión lukacsiana del "autismo decadentista", por cuanto, para él, un "style de décadence" se definiría como aquel en que "l'unité du livre se décompose pour laisser la place à l'indépendance de la page, où la page se décompose pour laisser la place à l'indépendance de la phrase, et la phrase pour laisser la place à l'indépendance du mot" (Bourget, 1883: 25).

No es la primera vez que el discurso de Hauser se aproxima al de dichos autores: a Nordau nos remite su apreciación de Barbey d'Aurevilly, Huysmans, Verlaine, Wilde y Beardsley como "hedonistas con remordimientos de conciencia" (Hauser, 1985: 218). Nordau, por cierto, no había dudado en incluir a Flaubert entre sus "degenerados", y había llegado a citar a Bouvard et Pécuchet casi como ilustración de la sintomatología en la que, para él, se reconocerían aquellos casos clínicomorales (Nordau, 1892: 491). En cuanto a Huysmans, el autor había comprendido el pasaje entre su "primera etapa" (la "naturalista", es decir, la "realista") y la "segunda" (la "decadente" o "diabolista") en clave de "abruptly contrasted methods", siendo una constante "obscenidad" el hilo conductor entre la una y la otra (Nordau, 1892: 302). De este modo, À rebours encarnaría un quiebre en la obra de Huysmans, entre una adhesión servil a los preceptos de Zola (Huysmans no fue nunca, dice Nordau, un hombre original) y la supuesta conversión del autor en epígono de Baudelaire. Des Esseintes sería, incluso, la encarnación misma del baudelairismo: "living, thinking, and acting" (Nordau, 1892: 299).

\section{4. "Realismo historicista" y "realismo existencialista"}

Sin llegar a adquirir semejante carga técnico-específica, el concepto de una "segunda mitad del siglo" se presenta también explícitamente en Mimesis. La representación de la realidad en la literatura occidental (1946), de Auerbach, vinculada ahora a una "mentalidad" que habría empezado a perfilarse ya en algunos de los románticos tardíos y comenzado a volverse dominante en la generación nacida hacia 1820. La exposición del autor se ha volcado ya al concepto "historicista" de realismo, en contraste con el realismo "ahistórico", "existencialista" 
(cfr. Wellek: 178, 179), que articularía el resto del volumen, y desde cuya óptica podría perfectamente haberse abordado la obra de los llamados "simbolistas" en beneficio del sentido, más acotado, de una corriente artístico-literaria. De ahí la considerable parcialidad que adquiere el estudio de Auerbach al llegar al siglo XIX. $\mathrm{Y}$ es que, en efecto, ¿no hacían alarde los "simbolistas" de una sed de realidad mucho más profunda, más auténtica que la de los "realistas"? El gesto es tanto más extraño cuanto se considera cómo para Auerbach -según apunta Ankersmit"realism exists solely in the variants through which it has manifested throughout the long course of history, [...] in [which] sense, the most meaningful thing to do is to recount the narrative of the history of realism" (Ankersmit, 1999: 55). Quizás sea también por ello que la noción de un Flaubert "realista" se conserva en gran medida tácita a través del texto, considerando cómo, en el marco de éste, semejante condición podría únicamente contrastarse con la muy débil construcción crítica que, en tales pasajes, efectúa el autor en torno a "lo fantástico".

Estas circunstancias acaban absorbiendo la potencia de ciertos nombres (Leconte de Lisle, Baudelaire o el propio Flaubert, por ejemplo) en cuanto a un eventual desarrollo de aquel elemento. Incluso una locución como "l'art pour l'art" se ve integrada, a través de Edmond de Goncourt, al campo problemático del realismo. Y sin embargo, la caracterización auerbachiana del arte y la literatura de esta etapa no se aparta, grosso modo, de la visión que hemos visto expresada ya a propósito de este aspecto. La gran figura que se opone aquí a los "realistas estéticos" es Zola; su feísmo no se daría, como sí en Goncourt, bajo la forma de su estetización, sino como respuesta a los grandes problemas sociales de su tiempo. No deja de ser significativo que el fragmento dedicado a Zola quede suspendido entre elogios y críticas benévolas, haciéndonos aguardar un grand finale -capaz de compensar las tendencias reclusivas del "l'art pour l'art"- que Auerbach proyecta discretamente hacia un mundo todavía por venir. El desplazamiento de la idea de un único y gran contraste estético-historiográfico (y, por ende, la de una segunda "mitad" del siglo igualmente comprendida como díptico) no impide al autor emplazar a Flaubert en el espacio de una ruptura radical con el pasado romántico, expresado en la tendencia a "ver por todas partes fuerzas secretas demoníacas e intensificar la expresión de las mismas hasta lo melodramático" (Auerbach, 1996: 454).

Al mismo tiempo, el autor caracteriza el tipo de obra que condensaría $A$ rebours en términos casi idénticos a los de Lukács, refiriéndose a aquellas obras narrativas de fines del siglo XIX "que intentaban producirnos una impresión de la realidad extremadamente individualista, subjetiva, a menudo excéntrica y que, sin duda alguna, no trataban de proporcionar algo universalmente válido u objetivo sobre la realidad o eran incapaces de ello" (Auerbach, 1996: 504, 505). Más adelante confirmará su valoración del texto de Huysmans en clave de una "visión cerrada y unipersonal de la realidad", contraponiendo la misma a la objetividad de la novela proustiana (Auerbach, 1996: 510). Tampoco vacila en contrastar el burgués "heroico", volcado a su papel revolucionario, de la época romántica con el "estúpido, perezoso, engreído, mendaz y cobarde bourgeois" (1996: 471). Fragmentos como los citados nos remiten a la cita doleželiana, pero también a la 
crítica de Hayden White en cuanto a que no se vería allí sino el signo de la ideología, notando cómo "Ideology or, as Barthes preferred to call it, 'mythical thought', worked in historical representation by surreptitiously substituing a Signified [...] to the Referent [...] it pretended merely to describe" (2010: 287). Para un autor como Lukács, es cierto, la evaluación de su propia escritura como "ideológica" lejos hubiera estado de constituir un insulto. Aun así, ello no basta para compensar la falacia metodológica puesta en juego.

Tales condiciones históricas se ven remitidas por Auerbach a una disposición comparable a la que, décadas más tarde, Rancière extendería a una caracterización general del régimen estético, considerándola esencial a una poética antirrepresentativa (cfr. Rancière, 2009: 13). En el caso de Auberbach, no obstante, se trata más bien de un concepto y un ideal del arte literario, supuestamente surgido a mediados de siglo, que "niega toda jerarquía en los temas" en conjunción tanto con la exaltación de la originalidad del escritor como del rechazo de la sumisión del arte a toda función "moral, política o impulsora de cualquier forma práctica de la vida del hombre" (Auerbach, 1996: 473). Autoridades más recientes han constatado igualmente esta coyuntura: así Bourdieu, a partir de un binomio idéntico al de la cita de Auerbach, se refirió al "rechazo a toda jerarquía entre los objetos y a toda función didáctica, moral o política" (1995: 206, 207); así Barthes, remontándose en su caso al romanticismo, había destacado cómo "el lastre arrojado al mezclar géneros y palabras le permitió [a la revolución romántica] preservar lo esencial el lenguaje clásico, la instrumentalidad" (2005: 15). También Jauss, siguiendo los razonamientos antes citados, aludió a cierta torsión entre la "vieja poesía de la naturaleza" y la nueva "poesía de la industria", entre "el historicismo del romanticismo final" y "un esteticismo incipiente, el del 'museo imaginario' de las artes que pretende disponer libremente del arte de todas las épocas del pasado, pero que, sin embargo, es incapaz de comprender el propio tiempo como una unidad epocal" (Jauss, 1989: 82).

Pero ya Nordau, en la década de 1890, había expuesto cómo Flaubert "avenged himself on the absurdity of his own efforts to conquer science as a lieutenant conquers a music-hall singer, by tarring and feathering Bouvard and Pécuchet" (Nordau, 1892: 162). Para Nordau, el decadente no era más que "an ordinary man with a minus signus, who, equally with the latter, only in a contrary sense, follows in the wake of the crowd" (1892: 306, 307). Tiempo después, Valéry sostendría que "Flaubert siempre fue asediado por el Demonio del conocimiento enciclopédico, al que trató de exorcizar escribiendo Bouvard y Pécuchet" (Valéry, 2010: 65); ese Demonio -retomado por Foucault en su famoso ensayo "La biblioteca fantástica" (1964) - que había llevado a Flaubert a ceder ante su propia tentation tanto en las obras "fantásticas" como en las "realistas", distinción cuyas limitaciones el propio Valéry reconoció implícitamente, especialmente en su abordaje de Salammbô (Valéry, 2010: 62). Cabe notar cómo este marco conceptual favorece la confusión entre el plano de la ficción literaria y el mundo empírico, no sólo en función de un vínculo meramente representacional entre uno y otro, sino en virtud de la articulación de ambos planos en (y no sólo a través de) el acto de escritura. Es que, 
en estos casos, el abordaje de cierto material exigiría del escritor una peculiar mimetización de sí mismo con sus criaturas: Flaubert debió convertirse en Bouvard y Pécuchet; fue imperioso para Huysmans conducirse como Des Esseintes.

Por lo demás, nos hemos referido ya a la imagen del Segundo Imperio en clave de una entronización del mal gusto, y a la vez -o como parte de ello- a la oficialización de ese "no-estilo" que habría de convertirse, paradójicamente, en el estilo mismo del siglo. El propio Bourget, en el texto sobre los Goncourt incluido en los Nouveaux essais de psychologie contemporaine (1886), había concebido el bibelot como lo que "a transformé la décoration de tous les intérieurs et leur a donné une physionomie d'archaïsme si continuellement curieuse et si docilement soumise que notre XIX ${ }^{\mathrm{e}}$ siècle, à force de colliger et de vérifier tous les styles, aura oublié de s'en fabriquer un" (Bourget, 1886: 149). Hemos citado ya, por otro lado, la opinión de Nordau al respecto. Es así como el límite entre el filisteo y el esteta comienza a desdibujarse, al parecer en beneficio del primero. También Praz, en $L a$ carne, la muerte y el diablo en la literatura romántica (1930), insistiría en la visión del siglo XIX como un tiempo "que tuvo todos los exotismos y los eclecticismos para distraer la intranquilidad de los sentidos exasperados y para compensar la falta de una profunda fe y de un auténtico estilo" (Praz, 1999: 768). Nos hallamos ahora, no obstante, ante parámetros críticos en gran medida diversos.

\section{Praz y el "Segundo romanticismo"}

Resulta comprensible que la categoría "después de 1848 " no hallase lugar en la obra más conocida de Praz, menos aun en el sentido que habrían de conferirle un Hauser o un Lukács. Si bien, como señala David Perkins, el autor italiano concedía que "external, sociological conditions have effects in literature", aquél a la vez "foregrounds a different conception of literary genesis by constructing the representation of a theme of a theme in successive works as a chain of causes, the prior ones determining the later" (Perkins, 1993: 115, 116). Praz mismo declararía, en la "Advertencia preliminar", que su propio estudio no tenía "ninguna conexión, ni siquiera remota, con un estudio sociológico o de psicología colectiva" (1999: 13). Es así como su exposición tiende a generar la ilusión de un estrato donde las distintas obras se comunicarían casi sin mediaciones, y en el que los autores intervendrían -al margen de las escasas remisiones biográficas- más bien en calidad de doleželianas "actual sources", definidas ante todo por su función de "provide the representation of fictional particular" (Doležel, 1988: 479). El efecto general es el de una esfera donde los mundos ficcionales encontrarían un plano de intercambio y, por ende, de conmensurabilidad; donde las criaturas de la ficción, e incluso ciertos sujetos empíricos (comenzando por los propios autores, convenientemente depurados de referencias "sociologizantes"), acabarían por resolver en importante medida sus desniveles ontológicos. El precio de ello es la reducción del nexo genético entre los materiales al "gusto y la moda", por citar las palabras del propio Praz (1999: 13). Un gusto y una moda de los que se ofrecen precisiones por demás escasas, de modo que la invocación al mundo "extra-literario", lejos de plantearse 
como una vía de problematización de la relación del arte con "lo histórico", opera más bien heurísticamente, haciendo operar el vacío de lo que no puede explicarse, sin más, desde el interior del flujo inmanente de los temas.

En contrapartida, la remisión a un vago "clima cultural" (Praz, 1999: 747) se traduce en la composición de una "atmósfera" de innegable elocuencia imaginaria. No extraña que llegase a verse en Praz el instaurador de una "nueva secuencia temporal" entre el romanticismo "tradicional" y un "Segundo romanticismo" (Segade, 2008: 16); tampoco el hecho de que esta visión tendiese a confundirse con los dualismos citados más arriba. Posible paradoja, por cierto, considerando tanto el esfuerzo de Praz por eludir los esquemas históricos más simplistas como el rigor filológico con que intentó concretarlo. Notaba así, en la "Advertencia preliminar", cómo Benedetto Croce "hubiese querido que yo señalara, con más profundidad, la diferencia entre el romanticismo propiamente dicho y el así llamado 'último romanticismo', que ha tomado también el nombre de 'decadentismo"' (Praz, 1999: 22). Sorprende que Praz se distanciase de esta postura casi sólo en la medida en que se había escrito ya abundantemente sobre el "arte por el arte" (según la noción que acerca de éste se desprende de la posición de Croce [1932: 57]), no habiendo por ello necesidad de insistir en términos a los que Praz mismo adhirió parcialmente. Y si, por otro lado, el crítico avaló cierta concepción del siglo XIX como una "totalidad única y diferente que las distintas fórmulas de romanticismo, verismo, decadentismo, etc., tienden a disgregar", al tiempo que percibía en el decadentismo finisecular "no más que una consecuencia" del romanticismo (Praz, 1999: 11), no sólo contribuyó, con este mismo gesto de distanciamiento, a jerarquizar a nivel teórico aquellas visiones que decía criticar: en más de una ocasión, de hecho, su figuración de fuertes dicotomías no hizo más que alimentar las visiones del siglo en clave "dualista".

De ahí la forma en que ubicó a Flaubert y de Baudelaire en la mitad misma del siglo XIX, entre "romanticismo y decadentismo, entre la época del hombre fatal y la de la mujer fatal, entre la época de Delacroix y la de Moreau" (Praz, 1999: 309). Si ya la crítica finisecular había dado un paso importante en la configuración de un "canon pos-romántico", Praz logró conferir al mismo una innegable dignidad crítica, tomando así distancia con respecto tanto a los muy divulgados abordajes pseudocientífico-morales (el de Nordau es un típico ejemplo) como de las aproximaciones más abiertamente poéticas, como la que el propio Huysmans concretara en $\dot{A}$ rebours. En este último aspecto, resulta notable el grado en que la propia escritura praziana llega a mimetizarse con su propio material, tornándose difícil -en diversa medida - discernir el grado en que tal organización se habría visto condicionada por factores inherentes a dicho material (o, planteado de otro modo, hasta qué punto no habría tenido el autor más remedio que acatarla). Rivalizando con el propio "enciclopedismo" decadente, Praz nos presenta así un verdadero catálogo de curiosidades, profuso en citas - casi al modo de un mosaico- y rico en personajes pintorescos, en temas recurrentes y en títulos resonantes, frecuentemente codificados como si de un bestiario se tratase. 
Parece evidente que el enfoque temático propuesto por Praz se vio favorecido por la adopción de términos como "simbolismo" o "decadentismo" como ejes de investigación, mientras que un término como "realismo" hubiera entorpecido sobremanera, ya desde su formulación a secas, una aproximación en clave semejante. No extraña que el autor pudiese prácticamente ignorar el realismo decimonónico, absolutizándose así la parcialidad de su enfoque (reconocida por él mismo en la "Advertencia preliminar") o que, en aquellos breves momentos en que el realismo aparece de algún modo referido (ante todo, a través de figuras autorales sólidamente asociadas al propio "realismo", como Zola), lo haga forzado dentro de una cuadrícula establecida de antemano a propósito, más bien, del arte y la literatura denominados "románticos". El Flaubert de Praz no es, ante todo, otro que el de Salammbô y la Tentation, el aficionado al "Oriente lujurioso y cruento", al "mundo antiguo lleno de vicios enormes y de delitos magníficos" (Praz, 1999: 319). También lo había sido, desde otra perspectiva, el de la edición de 1919 de The Symbolist Movement in Literature, de Arthur Symons. Pero ya Huysmans, en $\grave{A}$ rebours, había presentado a Flaubert bajo una óptica similar, al decir que Des Esseintes prefería, "chez Flaubert, La Tentation de saint Antoine à L'Education sentimentale" (así como, "chez de Goncourt, la Faustin à Germinie Lacerteux; chez Zola, La Faute de l'abbé Mouret à L'Assommoir)" (Huysmans, 1920: 176).

En cuanto al propio Huysmans, Praz se hizo eco de la valoración de À rebours como "libro cardinal del decadentismo", en el que no sólo las otras novelas del mismo autor, sino también "toda la prosa decadente, desde Lorrain hasta Gourmont, desde Wilde a D'Annunzio, está potencialmente contenida" (Praz, 1999: 567). Es por ello que el autor apenas se detiene sobre la novela de Huysmans, asumiendo que se trata de una obra muy conocida. También la filiación estético-ideológica atribuida a dicho libro, configurada como una prehistoria del decadentismo, respeta en gran medida la ortodoxia ya constituida en torno a la segunda "mitad" del siglo. En el personaje de Des Esseintes habrían confluido, desde esta óptica, el legado imaginario de Poe, la técnica flaubertiana y el más puro "baudelairianismo", pero también las nociones que Zola expresara sobre la decadencia "desde 1866" (Praz, 1999: 569). Tímido desdibujamiento, pues, de las fronteras entre "realismo" y "fantástico", cuya distinción Praz parece presuponer al tiempo que esboza el gesto de integrarlos (aunque sin llegar a resolver la asimetría el uno y el otro). Pero así como la obra de Flaubert se ve presentada a partir sus expresiones más obviamente "fantástico-decadentistas", la de Huysmans aparece escrupulosamente depurada de sus conexiones con respecto al "realismo" e incluso de su eventual oposición al mismo, favoreciéndose de este modo la visión absoluta de $\dot{A}$ rebours como una novela donde "toda la fenomenología de ese estado de ánimo [el decadente] es ilustrada hasta en sus más mínimos detalles” (Praz, 1999: 567).

\section{Rumbo al otro fin de siglo}

Todavía en ciertos "clásicos" de la crítica de fines del siglo pasado se observa una fuerte presencia del sedimento mítico referido, ratificado éste incluso desde la 
perspectiva del rigor sociológico-historiográfico al tiempo que reactualizándose los debates que, cien años antes, habían informado las más perdurables concepciones de la segunda "mitad" del siglo XIX. Es así como, en una obra como Las reglas del arte (1995 [1992]), Bourdieu retomó un sustrato terminológico comparable al que desplegara Albert Cassagne (1997 [1906]), autor de la que quizás fuera la primera gran obra en proponer un "projet d'histoire littéraire" en torno al "l'art pour l'art". La identificación de los "néo-romantiques" y los artepuristas por Cassagne había contribuido a consolidar cierta correlación entre una dimensión eminentemente temática (en cuya clave se reconocería con mayor evidencia ese "neorromanticismo" en oposición a un arte y una literatura "realistas"), por un lado, y el status deseado para el arte en el marco de la sociedad, por el otro. La época "après 1848" habría sido, de esta forma, un "temps décisif pour la structuration de l'art pour l'art" (Oster, 1997: 22), y a fortiori del creciente divorcio entre un término como "romanticismo" y la perspectiva de un arte sometido, ya al "compromiso" político-social, ya (o también) a lo que se suele figurarse, despectivamente, como "el utilitarismo burgués".

A estas circunstancias atribuyó Bourdieu una tendencia cada vez mayor del campo literario a organizarse en oposiciones comunes, de modo que ya hacia 1880 habría podido hablarse de una oposición más bien simétrica, trascendente en relación con la división en géneros, entre "simbolismo" y "naturalismo". Una oposición que no sería difícil comprender en los términos que también había sugerido Lukács a propósito del "período de la decadencia burguesa", señalando la aparición del antagonismo entre "objetivismo" e "irracionalismo" en "innumerables variantes, provocando incontables discusiones sobre la "esencia" del arte e infinidad de manifiestos y doctrinas" (1966: 143). Ante este panorama, Bourdieu emplazó a Flaubert en un lugar de trascendencia, emparentándolo en ello con aquel gran "héroe fundador" de la modernidad estética que fuera Baudelaire (Bourdieu, 1995: 100), y aun así reproduciendo, en los términos de esa misma operación crítica, la lectura de la obra flaubertiana en clave de dichas oposiciones. En cuanto a Huysmans, Bourdieu introdujo su figura en términos de una reacción "simbolista" contra el naturalismo, tratando al escritor parisino como ejemplo del "renacimiento espiritualista" contra la escuela zoliana, a la vez que estableciendo un lazo entre Huysmans mismo y la "gran" figura de Flaubert. De ahí su modo de señalar cómo, "más allá de sus diferencias", tanto el uno como el otro finalmente habrían compartido -en conjunto con autores como Baudelaire, Banville, Villiers, Barbey o Leconte de Lisle- su compromiso "con una obra que se sitúa en las antípodas de la producción sometida a los poderes o del mercado", siendo con ello "los primeros en formular con toda claridad los cánones de la nueva legitimidad" (Bourdieu, 1995: 99).

De esta revisión panorámica de este corpus se desprende, en todo caso, la importancia de considerar el grado en que la adopción de tales o cuales categorías llega a impactar sobre la distribución de los claroscuros de la historia, sobre la jerarquización de aquellos elementos (de todo orden, aunque referidos en última instancia a categorías narratológicas convencionales) que componen la misma en cuanto expresión narrativa. Por detrás de las mutaciones se vislumbra, por 
definición, algo así como una objetividad fenoménica, pero sólo parcialmente podría identificarse las mismas con diversos "puntos de vista" sobre esta última. Puesto que no se trata simplemente de diferentes "facetas" del mismo autor o del mismo "siglo XIX" (aunque concluyamos remitiendo ambas visiones al mismo referente empírico, en virtud de cierto horizonte ontológico), o siquiera de dos versiones, eventualmente incompatibles, de la misma "realidad", sino de universos histórico-ficcionales en gran medida autónomos y autoconclusivos. En el caso de nuestro material, ello aparece expresado, en gran medida, a través del modo en que el trazado de cierta cuadrícula crítica contribuye a la configuración de una atmósfera característica de una segunda "mitad" del siglo (incluso cuando, como en el caso de Praz, el autor rechazase expresamente una secuencia cronológica semejante). No nos estaríamos refiriendo, en definitiva, sino a las turbulencias que más o menos significativamente, y con un nivel superficialidad variable- agitarían el régimen escópico a través del cual la mirada del crítico-historiador se vuelve hacia el pasado, contribuyendo a la vez, y en ese mismo gesto, a conceptualizar su propio presente.

\section{REFERENCIAS BIBLIOGRÁFICAS}

Ankersmit, F. R., (1999) "Why Realism? Auerbach and the Representation of Reality" in Poetics Today. Vol. 20, $\mathrm{n}^{\circ} 1$ (Primavera), pp. 53-75.

Auerbach, E., (1996). Mimesis. La representación de la realidad en la literatura occidental. Trad. I. Villanueva y E. Ímaz. México D. F., FCE.

Bourget, P., (1883) Essais de psychologie contemporaine. París, Alphonse Lemerre.

Bourget, P., (1886) Nouveaux essais de psychologie contemporaine. París, Alphonse Lemerre.

Bourdieu, P., (1995) Las reglas del arte. Génesis y estructura del campo literario. Trad. Thomas Kauf. Barcelona, Anagrama.

Carboni, P., (2004) "Ossian and Belles Lettres: Scottish Influences on J.-B.-A. Suard and Late-Eighteenth-Century French Taste and Criticism" in Dwason, D. \& P. Morère (eds.), Scotland and France in the Enlightenment. Cranbury, Rosemont, pp. 74-89.

Cassagne, A., (1997) La théorie de l'art pour l'art en France chez les derniers romantiques et les premiers réalistes. Seyssel, Champ Vallon.

Croce, B., (1932) Storia d'Europa nel secolo decimonono. Bari, Laterza.

Doležel, L., (1988) "Mimesis and Possible Worlds" in Poetics Today. Vol. 9, n 3, Aspects of Literary Theory, pp. 475-496.

Flaubert, G., (1870) L'éducation sentimentale: histoire d'un jeune homme, Vol. 2. París, Michel Lévy Frères.

Foucault, M., (1964) "La biblioteca fantástica", trad: Ricardo Cano Gaviria [En línea]. Disponible en: http://www.con-versiones.com/nota1006.htm. [Último acceso el 29 de octubre de 2013].

Gamerro, C., (2003) Harold Bloom y el canon literario. Madrid, Campo de Ideas. 
Gorak, J., (2013) The Making of the Modern Canon: Genesis and Crisis of a Literary Idea. Londres, Bloomsbury.

Harvey, D., (2003) Paris, Capital of Modernity. Nueva York, Routledge.

Hauser, A., (1985) Historia Social de la Literatura y del Arte, Vol. 3. Trad: A.

Tovar y F. P. Varas-Reyes. Barcelona, Labor.

Huysmans, J.-K., (1920) A rebours. París, A. Ferroud - F. Ferroud.

Jauss, H.-R., (1989) Las transformaciones de lo moderno. Madrid, Visor.

Kellner, S., (2012) Maupassant, un météore dans le ciel littéraire de l'époque. París, Publibook.

Lukács, G., (1966) "La fisonomía intelectual de las figuras artísticas”, “¿Narrar o describir? A propósito de la discusión sobre naturalismo y formalismo" in Problemas del realismo. Trad. Carlos Gerhard. México D. F., FCE, pp. 125-170, 171-216.

Marx, K., (2003) El 18 Brumario de Luis Bonaparte. Buenos Aires, Prometeo.

McLeod, K., (2006) Fictions of British Decadence. High Art, Popular Writing, and the Fin de Siècle. Basingstoke, Palgrave Macmillan.

Nordau, M., (1892) Degeneration. Nueva York, Appleton \& Co.

Oster, D., (1979) "Préface" in Cassagne, A., La théorie de l'art pour l'art en France chez les derniers romantiques et les premiters réalistes. Seyssel, Champ Vallon, pp. 5-33.

Perkins, D., (1993) "Literary Histories and the Themes of Literature" in Sollors, W. (ed.), The Return of Thematic Criticism. Cambridge, Harvard University Press.

Praz, M., (1999) La carne, la muerte y el diablo en la literatura romántica. Trad: Rubén Mettini. Barcelona, El Acantilado.

Rancière, J., (2009) El reparto de lo sensible. Trad. Cristóbal Durán, Helga Peralta, Camilo Rossel, Iván Trujillo y Francisco de Undurraga. Santiago de Chile, LOM Ediciones.

Rapport, M., (2008) 1848: Year of Revolution. Nueva York, Basic Books.

Rees, K., (2010) Flaubert: Transportation, Progression, Progress. Berna, Peter Lang.

Rest, J., (1971) "Reseña de La carne, la muerte y el diablo en la literatura romántica, de Mario Praz" in Revista Los Libros. N¹7, pp. 24-25.

Rest, J., (1977) "Introducción" in J.-K. Huysmans, Al revés. Trad: Rodrigo Escudero [En línea]. Disponible en: http://es.scribd.com/doc/131861292/J-KHuysmans-AL-REVES. [Último acceso del 29 de octubre de 2013].

Samson, J., (2001) "The musical work and nineteenth-century history" in The Cambridge History of Nineteenth-Century Music. Cambridge, Cambridge University Press.

Sartre, J.-P., (1967) Baudelaire. Trad. Martin Turnell. Nueva York, New Directions. Sartre, J.-P., (1971-72) L'idiot de la famille: Gustave Flaubert de 1821 à 1857.

París, Gallimard.

Segade, M., (2008) Narciso fin de siglo. Barcelona: Melusina.

Symons, A., (1919) The Symbolist Movement in Literature. Nueva York, E. P. Putton. 
Stephan, Ph., (1974) Paul Verlaine and the Decadence, 1882-90. Totowa, University of Manchester.

Tollinchi, E., (2004) Los trabajos de la belleza modernista. 1848-1945... San Juan, Editorial de la Universidad de Puerto Rico.

Valéry, P., (2010) De Poe a Mallarmé. Ensayos de poética y estética. Buenos Aires, El cuenco de plata.

Weir, D., (1995) Decadence and the Making of Modernism. Amherst, University of Massachusetts Press.

Wellek, R., (1968) "El concepto de romanticismo en la historia literaria" in Conceptos de crítica literaria. Caracas, Ediciones de la Biblioteca de la Universidad Central de Venezuela, pp. 103-152.

White, H., (2011) La ficción de la narrativa. Ensayos sobre historia, literatura y teoría, 1957-2007. Trad. María Julia de Ruschi. Buenos Aires, Eterna Cadencia. 